\title{
PENGARUH MARKET ORIENTATION TERHADAP SERVICE QUALITY, SATISFACTION DAN LOYALTY PELANGGAN TOKO BUKU GRAMEDIA DI JAWA TIMUR
}

\author{
FX Agus Subroto \\ STIE Indonesia Malang, Indonesia \\ Email: dragus.subroto@gmail.com
}

\begin{abstract}
Abstrak
Penelitian ini bertujuan membuktikan dan menganalisis pengaruh orientasi pasar terhadap kualitas layanan, kepuasan dan loyalitas pelanggan. Jumlah sampel penelitian 144 pelanggan. Analisis data dilakukan dengan menggunakan Structural Equation Modelling (SEM) dengan program AMOS. Hasil penelitian ini adalah orientasi pasar berpengaruh signifikan terhadap kualitas layanan; orientasi pasar berpengaruh signifikan terhadap kepuasan; orientasi pasar tidak berpengaruh signifikan terhadap loyalitas pelanggan; kualitas layanan berpengaruh signifikan terhadap kepuasan pelanggan; kualitas layanan tidak berpengaruh signifikan terhadap loyalitas pelanggan; kepuasan pelanggan berpengaruh signifikan terhadap loyalitas pelanggan.
\end{abstract}

Kata kunci: Orientasi Pasar, Kualitas Layanan, Kepuasan Pelanggan, Loyalitas Pelanggan.

\begin{abstract}
The research objectives were to prove and to analyze the effect of market orientation on service quality, customer satisfaction and loyalty. The research sample consisted of 144 customers. The data were analyzed using Structural Equation Modeling (SEM) with AMOS. The results proved that market orientation had significant effect on service quality; market orientation had significant effect on satisfaction; market orientation had no significant effect on customer loyalty; service quality had significant effect on satisfaction; service quality had no significant effect on customer loyalty. Customer satisfaction had significant effect on customer loyalty.
\end{abstract}

Keywords: Market Orientation, Service Quality, Customer Satisfaction, Customer Loyalty.

\section{PENDAHULUAN}

Perubahan teknologi merupakan kekuatan pendorong utama ke arah globalisasi, dan perubahan teknologi jelas saling mendukung. Kotter \& Heskett (1992) mengatakan bahwa globalisasi yang meningkat berarti persaingan juga meningkat, persaingan meningkat menuntut perubahan ke arah pendekatan relasional dengan berfokus pada pemenuhan kebutuhan, kepuasan dan kesenangan pelanggan. Artinya pelanggan tidak dibiarkan berlalu begitu saja, pelanggan harus disapa, dilayani kebutuhannya maupun keinginannya sebaik baiknya melalui pendekatan diri. Mendekatkan diri dengan pelanggan bertujuan untuk memahami kebutuhan dan harapan pelanggan, dengan memahami kebutuhan para pelanggan target memungkinkan perusahaan untuk mengkoordinasi semua aset-aset dan memungkinkan pula perusahaan untuk meningkatkan value (nilai) bagi pelanggan. Hasil tersebut akan menciptakan service (layanan) yang superior bagi pelanggan. Sebagai contoh, Selnes et al. dalam Narver \& Slater (1990) mengatakan bahwa di sisi internal pengembangan market orientation secara umum, menuju pada sikap kerja, komitmen dan semangat team yang positif bagi para karyawan perusahaan. Di sisi eksternal, sikap kerja, komitmen dan semangat tim tersebut akan berdampak terhadap pengembangan service quality bagi kepuasan pelanggan. Menurut Zeithaml et al. (1994) menyatakan bahwa Lima dimensi service quality, sangat berpengaruh terhadap tercapainya satisfaction pelanggan. Salah satu cara untuk mempertahankan pelanggan menurut Fornell (1992) adalah dengan meningkatkan satisfaction yang ada. Faktor-faktor yang mempengaruhi satisfaction dapat diketahui bila perusahaan mengenal apa yang dibutuhkan pelanggan. Pengetahuan mengenai kebutuhan pelanggan sangat penting karena akan memberi 
warna atau suatu pemahaman yang lebih baik mengenai cara pelanggan mengartikan service quality (kualitas barang atau jasa) perusahaan. Dimensi satisfaction bagi pelanggan menurut Dutka (1994), tercermin dalam tiga dimensi, yakni attributes related to the product, attributes related to service dan attributes related to purchase. Pelanggan mungkin akan puas apabila bisa membeli barang paling murah dan bermutu. Di lain pihak pelanggan akan puas apabila dilayani dengan baik, serta pelanggan akan puas apabila ada jaminan atas barang yang dibeli. Hasil evaluasi pelanggan pada akhirnya akan mengarah kepada satisfaction maupun dissatisfaction. Griffin, (2003) menyatakan bahwa satisfaction dapat menciptakan loyalty pelanggan, baik loyalty lemah, tersembunyi maupun premium loyalty atau bahkan tanpa terciptanya loyalty. Cronin et al. (2000) telah membuktikan bahwa satisfaction bisa mendorong perilaku pelanggan yang diinginkan yaitu minat untuk membeli ulang pada produk dan jasa perusahaan. Pendapat Irawan (2002) satisfaction merupakan inti dari keseluruhan marketing strategy, sehingga organisasi harus care. Satisfaction yang rendah dapat menyebabkan banyak kerugian secara finansial bagi perusahaan maupun kerugian non finansial misal image perusahaan, Bly (2003).

Thoyib, (1998) menyatakan bahwa pengelolaan bisnis retail tidak sekedar hanya membuka toko dan mempersiapkan barang-barang yang lengkap, tetapi lebih dari itu. Hal tersebut juga ditekankan oleh Berman dan Evans (2004) bahwa pengelolaan bisnis retail harus melihat, mengikuti perkembangan teknologi pemasaran agar dapat berhasil dan mempunyai keunggulan bersaing Semakin tajam persaingan di bisnis retail, baik nasional maupun asing berdampak pada perkembangan bisnis retail. Bagi perusahaan yang kurang siap dengan perubahan pasti kesulitan menghadapi tantangan, khususnya bisnis retail internasional yang telah mulai merambah Indonesia.

Adapun rumusan masalah adalah sebagai berikut (a) apakah market orientation berpengaruh signifikan terhadap service quality Toko Buku Gramedia di Jawa Timur?; (b) apakah market orientation berpengaruh signifikan terhadap satisfaction pelanggan Toko Buku Gramedia di Jawa Timur?; (c) apakah market orientation berpengaruh signifikan terhadap loyalty pelanggan Toko Buku Gramedia di Jawa Timur?; (d) apakah service quality berpengaruh signifikan terhadap satisfaction pelanggan Toko Buku Gramedia di Jawa Timur?; (e) apakah service quality berpengaruh signifikan terhadap loyalty pelanggan Toko Buku Gramedia di Jawa Timur?; (f) apakah satisfaction pelanggan berpengaruh signifikan terhadap loyalty pelanggan Toko Buku Gramedia di Jawa Timur?

\section{LANDASAN TEORI DAN HIPOTESIS}

Market Orientation merupakan budaya bisnis yang menjalankan organisasi ke arah penciptaan nilai yang bermutu bagi konsumen secara terus menerus (Narver \& Slater, 1990) Tema di atas akan mengungkap tiga konseptualisasi dominan bagi penciptaan dan pemberian nilai yang bermutu bagi pelanggan. Pertama, Kohli dan Jaworski (1990) menguraikan konseptualisasi market orientation yang mengacu pada penciptaan intelejen pasar yang berkenan dengan kebutuhan pelanggan saat ini dan mendatang, penyebaran intelejen lintas departemen, dan respon organisasi terhadap intelejen tersebut. Segi utama dalam pandangan ini adalah fokus pada pasar, yakni sebuah penekanan pada bentuk interfunctional coordination tertentu, dan fokus pada aktivitas terkait dengan pemrosesan informasi. Kedua, Narver dan Slater (1990) telah menyempurnakan pandangan Kohli dan Jaworski (1990), mengatakan bahwa market orientation terdiri dari tiga komponen pelaku (customer orientation, competitor orientation dan inter functional coordination merupakan aktivitas perolehan informasi pasar dan penyebaran serta penciptaan nilai konsumen yang terkoordinasi. Ketiga, Deshpande et al. (1993) mendefinisikan market orientation sebagai bentuk kepercayaan yang memperhatikan kepentingan konsumen terlebih dahulu, selain itu juga menciptakan profit. Deshpande \& Farley (1998) dalam hal ini mensintesakan tiga konseptualisasi yaitu dengan mendefinisikan market orientation sebagai bentuk proses lintas fungsi dan aktivitas di arahkan pada penciptaan nilai bermutu bagi konsumen melalui penilaian kebutuhan terus menerus Narver \& Slater (1990) menjelaskan hubungan antara keunggulan kompetitif dan market orientation. Gambaran market orientation sebagai sebuah business culture yang sangat efektif dan efisien mampu menghasilkan superior value bagi pelanggannya. Berbasis pada konsep keunggulan kompetitif, diargumentasikan bahwa satu-satunya cara untuk mencapai superior performance adalah melalui penciptaan superior value bagi masingmasing pelanggan.

Keinginan menciptakan superior value dan berkeunggulan bersaing akan merangsang perusahaan menciptakan dan memelihara budaya korporat yang dapat menghasilkan perilaku market orientation tersebut. Kohli \& Jaworski (1990) menyimpulkan, budaya perusahaan sangat efektif dan efisien memunculkan perilaku yang dibutuhkan guna menghasilkan superior value performance bagi perusahaan, serta melanggengkan kinerja. 
Atas dasar telaah pustaka-pustaka perilaku dan pemasaran, Narver \& Slater (1990) menarik kesimpulan bahwa market orientation terdiri dari tiga komponen perilaku yaitu customer orientation, competitor orientation dan interfunctional coordination yang mengarah pada dua kriteria keputusan yaitu long term focus dan profitability. Bila disimak lebih mendalam customer orientation dan competitor orientation sesungguhnya mencakup semua kegiatan yang ditujukan untuk mendapatkan informasi mengenai customer dan competitor dalam pasar target. Pustaka-pustaka menyimpulkan bahwa ketiga komponen perilaku itu mempunyai derajat urgensi atau tingkat kepentingan yang sama, oleh karena itu konsep market orientation yang digambarkan dalam sebuah segitiga sama sisi. Gambar 1 menunjukkan bahwa kinerja suatu perusahaan dihasilkan dan ditingkatkan melalui suatu pemusatan perhatian pada: (a) Customer orientation melalui pemahaman yang cukup atas pembeli-pembeli sasaran. (b) competitor orientation.

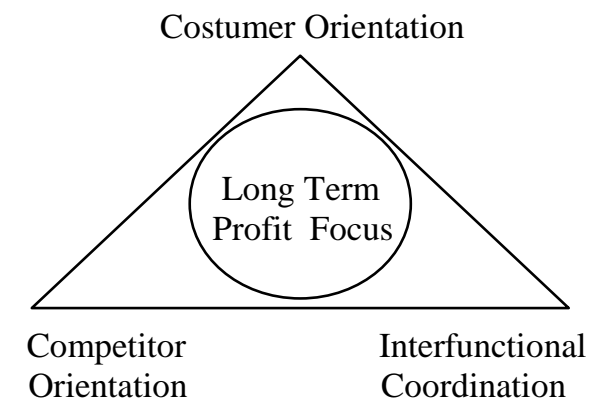

Gambar 1. Market Orientation

Sumber: Narver dan Slater (dalam Ferdinand, 2002)

Seorang penjual memahami kekuatan dan kelemahan saat ini serta kapabilitas dan strategi jangka panjang pesaing yang potensial. (c) Interfunctional coordination utilisasi sumber daya perusahaan yang terkoordinasi melalui semua bagian organisasi perusahaan untuk menciptakan superior value bagi pelanggan sasaran.

Perusahaan-perusahaan yang mengadopsi market orientation akan menikmati penilaianpenilaian kualitas dan pelaksanaan finansial yang unggul, dasar pemikiran ini dikemukakan Avionitis \& Gounaris (dalam Chang \& Chen, 1998) sekali market orientation telah dikembangkan, kemampuan perusahaan akan menghasilkan pelayanan superior, karena memungkinkan pemahaman yang lebih baik dari kebutuhan pasar target. Memahami kebutuhan para pelanggan target memungkinkan perusahaan untuk mengkoordinasi semua asset-aset, dan memungkinkan pula perusahaan untuk meningkatkan nilai bagi pelanggan. Sebagai contoh, Selnes et al. (dalam Narver \& Slater, 1990) menyatakan bahwa mengembangkan market orientation secara umum, menuju pada sikap kerja, komitmen dan semangat team yang positif untuk para karyawan perusahaan. Hal ini penting untuk sektor jasa terutama untuk personel yang menempati posisi garis depan atau ujung tombak perusahaan. Pelham dan Wilson (1996) dalam penelitian mereka mengenai market orientation pada perusahaan-perusahaan kecil membuktikan adanya pengaruh yang kuat dan konsisten dari market orientation atas berbagai indikator kinerja perusahaan kecil. Mereka berargumentasi bahwa dalam lingkungan kompetisi yang hostile (dengan tingkat persaingan tinggi kompetisi pada lingkungan mempunyai tingkat hostilitas yang tinggi). Sebagai perusahaan kecil merespon persaingan dengan memberikan perhatian besar pada kegiatan-kegiatan dan perilaku market oriented. Sementara perusahaan lainnya melakukan respon melalui pengendalian biaya dan pemotongan harga. Hal menarik dari studi ini adalah bahwa perusahaan-perusahaan yang merespon tekanan persaingan harga melalui strategi biaya rendah dalam jangka pendek berhasil meningkatkan sharenya. Akan tetapi, perhatian yang sangat memuaskan pada strategi ini tidak terlalu berdampak pada profitabilitas dan kinerja jangka panjang. Harapan bahwa market orientation dapat mempengaruhi pandangan perusahaan dalam mengembangkan strategi bersaing. Hal ini terutama dapat diruntut akarnya pada literature yang menandaskan bahwa market orientation ini akan menciptakan sebuah setting kondusif bagi aktivitas organisasi yang efektif dan efisien, untuk menghasilkan kinerja superior (Jaworski \& Kohli, 1993; Kohli \& Jaworski, 1990; Narver \& Slater, 1990). Pengaruh market orientation dapat dilihat dalam proses formulasi faktor-faktor stratejik terpilih yang dapat mempengaruhi kinerja perusahaan, seperti pertimbangan dan keputusan mengenai produk yang menguntungkan, kecocokan produk. Asumsiasumsi pengelolaan pemasaran perusahaan dianut para manager adalah asumsi sensitivitas terhadap pesaing, baik pesaing aktual maupun pesaing potensial. Oleh karena itu perusahaan akan bertindak rasional dengan mengembangkan strategi kompetisi melawan atau berhadapan dengan pesaing. Cara terbaik untuk menghasilkan kinerja perusahaan dalam pasar kompetitif adalah dengan memusatkan perhatian bukan pada pesaing tetapi pada pelanggannya. Ini berarti bahwa, rasionalitas ekonomi akan menuntun menajemen perusahaan untuk memperhatikan kepentingan pelanggan dari pada meniru dan mengadaptasi strategi pesaing. Akan lebih baik memilih untuk memusatkan upaya guna mengikat pelanggan poten- 
sial dengan mengembangkan strategi strategi customer oriented. Hal ini mempunyai pengaruh untuk jangka panjang.

Dalam upaya memperluas pandangan-pandangan teoritis yang ada, market orientation mempunyai pengaruh yang sangat bermakna terhadap naik turunnya kinerja perusahaan. Analisis mengenai market orientation diarahkan untuk mempostulasikan sebuah hubungan antara market orientation dan keunggulan bersaing berkelanjutan melalui kinerja pasar yang di hasilkan. Dalam kerangka demikian, pertanyaan dapat dimunculkan, bagaimana market orientation mempengaruhi kinerja pemasaran dan bagaimana keduanya mempengaruhi keunggulan bersaing yang berkelanjutan?

Service Quality mempunyai kontribusi besar terhadap satisfaction pelanggan, retention pelanggan, komunikiasi getok tular, pembelian ulang, loyalty pelanggan, pangsa pasar, serta profitabilitas perusahaan. Hal ini diperkuat dengan hasil sejumlah studi menunjukkan bahwa, ROI (Return on Investment), ROA (Return on Assets) dan perputaran aset sangat terkait dengan persepsi service quality ( barang atau jasa) suatu perusahaan. Riset terakhir Zeithaml et al. (1994) menyederhanakan service quality menjadi lima dimendi, yaitu: reliability; responsiveness; assurance; empathy; tangibles. Dalam mendefinisikan service quality ada beberapa karakteristik tambahan patut untuk diperhitungkan yaitu dari Lovelock dan Wright (2005) mengidentifikasikan delapan dimensi quality (8P) dua diantaranya adalah antara product, promotion Akan tetapi dimensi tersebut lebih tepat diterapkan di dalam perusahaan fabrikan.

Dimensi Service Quality banyak dimensi service quality dikemukakan beberapa peneliti. Berikut ini pendapat Parasuraman \& Berry (dalam Tjiptono \& Chandra, 2005) berhasil mengidentifikasi sepuluh dimensi pokok dari service quality, yaitu: (a) Reliabilitas (b) Responsivitas (c) Kompetensi (d) Akses, (e) Kesopanan (courtesy), (f) Komunikasi (g) Kredibilitas h) Keamanan (security) i) Kemampuan memahami pelanggan, (j) Bukti-bukti fisik (tangibles), yaitu meliputi penampilan fasilitas fisik.

Dalam riset berikutnya, mereka menyederhanakan menjadi lima dimendi, yaitu: (a) Reliability (reliabilitas) berkaitan dengan kemampuan perusahaan untuk memberikan layanan yang akurat. (b) Responsiveness (daya tanggap), berkenaan dengan kesediaan dan kemampuan para karyawan untuk membantu para pelanggan serta merespon permintaan mereka. (c) Assurance (jaminan), yaitu: perilaku karyawan mampu menumbuhkan kepercayaan pelanggan terhadap perusahaan bisa menciptakan rasa aman bagi para pelanggannya. (d) Empathy (empati), memahami masalah pelanggan dan bertindak demi kepentingan pelanggan. (e) Tangibles (bukti fisik), berkenaan dengan daya tarik fasilitas fisik, perlengkapan dan material yang digunakan perusahaan. Penyebab buruknya Service Quality: Service Quality merupakan salah satu faktor dari satisfaction pelanggan, sehingga perusahaan wajib mempertahankan komitmen tersebut. Namun kenyataan dilapangan ditemui juga, pelanggan merasa dikecewakan oleh service quality (kualitas layanan) penyadia jasa. Penyebab faktor buruknya service quality adalah sebagai berikut: (a) Intensitas tenaga kerja yang tinggi (b) Produksi dan konsumsi terjadi secara simultan (c) Dukungan terhadap pelanggan internal kurang memadai (d) Gap komunikasi (e) Memperlakukan semua pelanggan dengan cara yang sama (f) Pengembangan jasa secara berlebihan. (g) Visi bisnis jangka pendek

Perbaikan service quality merupakan pekerjaan yang tidak mudah. Kendala yang harus dipertimbangkan dengan cermat, menjadi pertimbangan utama yaitu (a) mengidentifikasikan pelanggan. (b) Mengelola ekspektasi pelanggan. c) Mengelola bukti kualitas jasa. (d) Mendidik konsumen tentang jasa. (e) Menumbuhkan budaya kualitas. (f) Menciptakan automating quality. g) Penyempurnakan jasa (h) Informasi SQ

Satisfaction menurut Kotler (2000) adalah 'Ungkapan perasaan senang atau kecewa seseorang, disebabkan oleh kinerja suatu produk atau jasa berkenaan dengan maksud yang diharapkan". Satisfaction ini menyangkut kesesuaian jasa yang diharapkan dengan kenyataan diterima pelanggan. Pendapat Oliver (1997) satisfaction pelanggan dirumuskan sebagai evaluasi pasca pembelian di mana persepsi terhadap kinerja dari alternatif produk atau service dipilih melebihi harapan maka terjadilah satisfaction. Apabila kenyataan service diterima pelanggan adalah service di bawah harapannya, maka pelanggan tidak puas, maupun sebaliknya. Menurut Dutka (1994) definisi atribut-atribut pembentukan satisfaction secara universal memuat tentang bagaimana pelanggan menilai suatu produk atau layanan. Bila ditinjau dari sudut pandang pelanggan, atribut-atribut dari satisfaction tersebut adalah sebagai berikut: (a) Atributes relate to the product; (b) Atributes related to service; (c) Atributes related to purchase. Gambar 2, menjelaskan jika pengalaman (kenyataan layanan yang diberikan) lebih kecil dari pada harapan konsumen, maka pelayanan tersebut dianggap buruk. Sebaliknya jika pengalaman (kenyataan layanan yang diberikan kepada konsumen) lebih besar dari pada yang di harapkan konsumen, pelayanan tersebut baik. 


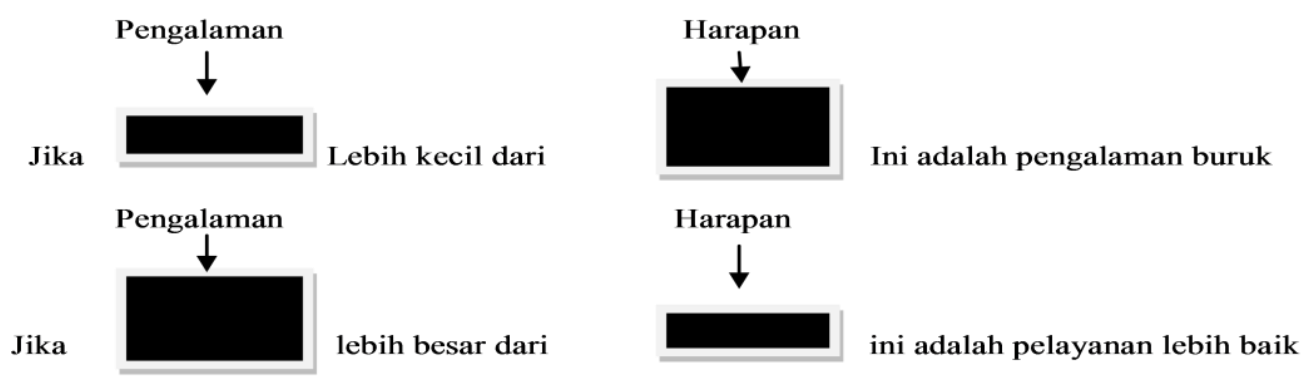

Sumber: Hopson dan Scally (1995)

Gambar 2. Harapan Konsumen

Sumber: Hopson dan Scally (1995)

Secara singkat, satisfaction di atas terdiri atas tiga komponen, yaitu: 1) Satisfaction merupakan respon (emosional atau kognitif); 2) Respon mengenai fokus tertentu (ekspektasi, produk, pengalaman konsumsi); 3) Respon terjadi pada waktu tertentu (setelah konsumsi, setelah pilihan produk atau jasa, berdasarkan pengalaman akumulatif

Loyalty pelanggan menurut Bowen dan Chen (2001) menganut tiga pendekatan berbeda dalam mengukur loyalty: (a) pengukuran kelakuan, pengukuran kelakuan mempertimbangkan kelakuan pembeli konsisten dan berulang sebagai indikator loyalty; (b) pengukuran sikap menggunakan data sikap untuk mencerminkan pelengkap emosi dan psikologi yang melekat dalam loyalty; (c) pendekatan ketiga, pengukuran gabungan, mengkombinasikan dua dimensi pertama (kelakuan dan sikap). Penggunaan sikap dan kelakuan dalam definisi loyalty pada dasarnya meningkatkan loyalty yang diperkirakan (Pritchard \& Howard 1997). Untuk penelitian ini, para pelanggan loyal adalah para pelanggan yang memiliki sikap menyenangkan terhadap perusahaan atau komitmen untuk membeli kembali produk/jasa dan merekomendasikan produk/ jasa pada orang lain. Menurut Griffin (2003) loyalty ada empat macam/ jenis, sebagai berikut: (a) no Loyalty yaitu beberapa pelanggan tidak mengembangkan loyalty terhadap produk atau jasa tertentu. Tingkat attachment rendah terhadap layanan dikombinasikan dengan tingkat pembelian berulang rendah menunjukkan tidak adanya loyalty. Secara umum perusahaan harus menghindari untuk membidik para pembeli jenis ini, karena mereka tidak akan pernah menjadi pelanggan loyal; (b) inertia loyalty yakni attachment rendah digabung dengan pembelian berulang tinggi menghasilkan inertia loyalty. Pelanggan ini membeli karena kebiasaan. Loyalty jenis ini paling umum terjadi pada produk yang sering dibeli. Pembeli ini rentan beralih ke produk pesaing yang dapat menunjukkan manfaat jelas, memungkinkan perusahaan untuk mengubah inertia loyalty ke dalam bentuk loyalty lebih tinggi dengan secara aktif mendekati pelanggan dan meningkatkan diferensiasi positif di benak pelanggan mengenai produk atau jasa dibanding produk lain; (c) latent loyalty (loyalitas tersembunyi) yaitu tingkat preferensi relatif tinggi digabung dengan tingkat pembelian berulang rendah menunjukkan latent loyalty. Bila pelanggan memiliki latent loyalty, pengaruh situasi dan bukan pengaruh sikap menentukan pembelian berulang. Dengan memahami faktor situasi yang berkontribusi pada latent loyalty, perusahaan dapat menggunakan strategi untuk mengatasi; (d) premium loyalty (loyalitas premium) loyalty jenis ini paling dapat ditingkatkan, terjadi bila ada tingkat keterikatan tinggi dan tingkat pembelian berulang juga tinggi. Ini merupakan jenis loyalty lebih disukai untuk semua pelanggan di setiap perusahaan. Pada tingkat preferensi paling tinggi tersebut, orang bangga karena menemukan dan menggunakan produk tertentu dan senang membagi pengetahuan. Para pelanggan ini menjadi pendukung vokal produk atau jasa dan selalu menyarankan orang lain (rekan atau keluarga) untuk membelinya.

Hipotesis dalam penelitian ini adalah a) Ada pengaruh signifikan market orientation terhadap service quality pelanggan Toko Buku Gramedia diJawa Timur; b) Ada pengaruh signifikan market orientation terhadap satisfaction pelanggan Toko Buku Gramedia di Jawa Timur; c) Ada pengaruh signifikan market orientation terhadap loyalty pelanggan Toko Buku Gramedia di Jawa Timur; d) Ada pengaruh signifikan service quality terhadap satisfaction pelanggan Toko Buku Gramedia di Jawa Timur (e) Ada pengaruh signifikan service quality terhadap loyalty pelanggan Toko Buku Gramedia di Jawa Timur; e) Ada pengaruh signifikan satisfaction terhadap loyalty pelanggan Toko Buku Gramedia di Jawa Timur. 


\section{METODE PENELITIAN}

Rancangan metode utama penelitian ini adalah penelitian survei, yaitu: metode pengumpulan data primer yang diperoleh langsung dari sumber asli (pelanggan) melalui kuesioner. Metode penelitian ini memerlukan kontak antara peneliti dengan subjek peneliti dalam hal ini responden. Manfaatnya yaitu untuk memperoleh data yang diperlukan. Sumber responden yaitu pelanggan Toko Buku Gramedia di Jawa Timur, minimal pembelian buku satu kali dalam dua bulan. Penelitian ini bisa disebut juga penelitian penjelas (explanatory research) karena tujuan penelitian ini adalah menjelaskan hubungan kausal antar empat variabel melalui pengujian hipotesis. Menurut Singarimbun (1995) bahwa pelaksanaan penelitian dilakukan dengan cara insidentil, yaitu: melakukan penelitian saat peneliti atau asisten peneliti bertemu langsung dengan responden. Data primer dapat terserap dari para pelanggan sebagai responden melalui pemberian kuesioner yang dapat langsung diisi. Proses penelitian dengan menggunakan metode ini dapat langsung memanfaatkan pelanggan yang sudah membeli atau membeli ulang buku tetap tidak termasuk pembelian alat-alat tulis. Materi riset tentang pengaruh market orientation terhadap service quality dan satisfaction maupun loyalty dalam studi kasus perdagangan retail (buku). Lingkup penelitian dibatasi pada teori pemasaran. Untuk mencapai tujuan itu, maka diperlukan suatu dukungan sumber data yang relevan, berupa data sekunder dari perusahaan (Gramedia di Jawa Timur). Selain itu diperlukan dukungan referensi yang mendukung penelitian ini, agar penelitian tersebut lebih terarah. Pemilihan Toko Buku Gramedia sebagai objek penelitian, disebabkan: Toko Buku Gramedia sebagai toko buku terbesar di Indonesia, mempunyai jaringan atau cabang terbanyak serta keunggulan lainnya yaitu kelengkapan produk buku. Omzet penjualan buku juga lebih besar bila dibanding dengan toko buku lain, sehingga bisa dijadikan acuan toko buku yang lain, sehingga Toko Buku Gramedia di Jawa Timur bisa dijadikan bahan acuan toko buku yang lain.
Populasi dalam penelitian ini adalah semua pelanggan yang pernah berbelanja buku, minimal satu kali dalam dua bulan di Toko Buku Gramedia di Jawa Timur. Alasan minimal satu kali dalam dua bulan adalah: (a) terbitan buku-buku baru untuk pelajar dan mahasiswa satu penerbit saja (contoh: Elexmedia Komputindo) antara 15-25 judul buku perbulan; (b) apabila dibatasi populasi pelanggan yang berbelanja enam bulan atau setahun sekali maka momen buku tersebut sudah hilang; (c) buku yang menumpuk dan enam bulan tidak terjual, akan dikembalikan ke penerbitnya; (d) sedangkan apabila populasi pelanggan yang berbelanja di toko buku Gramedia yakni satu bulan sekali adalah terlalu cepat buat pelajar/ mahasiswa, karena hal ini dikaitkan dengan penghasilan tiap bulannya; (e) diambil jalan tengah untuk kepentingan kedua belah pihak. Hasil jawaban kuesioner dari responden yang dikumpulkan berupa data primer. Sampel penelitian tersebut di atas diharapkan representative, artinya sampel tersebut bisa mewakili populasi. Sampel pada penelitian ini adalah pelanggan di enam toko buku Gramedia Surabaya, Malang dan Jember, (JawaTimur). Tabel 1 menunjukkan proporsi jumlah toko buku terhadap jumlah sampel yang dibutuhkan. Dari masing-masing kota dengan sampel masing-masing mewakili berbanding lurus dengan banyaknya toko, sampel dibatasi yaitu pelanggan yang pernah berbelanja buku minimal satu kali dalam dua bulan dan saat itu sedang berbelanja buku di Toko Buku Gramedia.

\section{Tabel 1. Populasi dan Sampel Penelitian}

\begin{tabular}{clcc}
\hline No & $\begin{array}{c}\text { Toko Buku } \\
\text { Gramedia }\end{array}$ & $\begin{array}{c}\text { Jumlah } \\
\text { Toko Buku }\end{array}$ & $\begin{array}{c}\text { Sampel } \\
\text { Responden }\end{array}$ \\
\hline 1 & Surabaya & 3 & 75 \\
2 & Malang & 2 & 50 \\
3 & Jember & 1 & 25 \\
\hline & Total & $\mathbf{6}$ & $\mathbf{1 5 0}$ \\
\hline
\end{tabular}

Sumber: Data primer di olah

Analisis Deskriptif dipergunakan untuk menganalisis data yang sudah dikumpulkan dan dipergunakan untuk mengidentifikasikan karakteristik masingmasing responden. Analisis Kuantitatif berdasarkan

Tabel 2. Identifikasi Variabel Penelitian

\begin{tabular}{|c|c|c|c|c|}
\hline Hipotesis & Variabel Eksogen & Indikator & Variabel Endogen & Indikator \\
\hline 1 & Market Orientation & $\mathrm{X}_{1.1} \mathrm{sd} \mathrm{X} \mathrm{X}_{1.3}$ & Service Quality & $\mathrm{Y}_{1.1} \mathrm{sd} \mathrm{Y}_{1.7}$ \\
\hline 2 & Market Orientation & $\mathrm{X}_{1.1} \operatorname{sd} \mathrm{X}_{1.3}$ & Satisfaction & 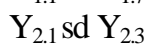 \\
\hline 3 & Market Orientation & $\mathrm{X}_{1.1} \operatorname{sd} \mathrm{X}_{1.3}$ & Loyalty & $Y_{3.1}{\operatorname{sd~} Y_{3.3}}$ \\
\hline 4 & Service Quality & $\mathrm{Y}_{1.1} \mathrm{sd} \mathrm{Y}_{1.7}$ & Satisfaction & $Y_{2.1} s d_{2.3}$ \\
\hline 5 & Service Quality & $\mathrm{Y}_{1.1} \mathrm{sd} \mathrm{Y}_{1.7}$ & Loyalty & $Y_{3.1} s Y_{3.3}$ \\
\hline 6 & Satisfaction & $Y_{2.1} s_{d} Y_{2.3}$ & Loyalty & $Y_{3.1} s Y_{3.3}$ \\
\hline
\end{tabular}

Sumber: Data primer diolah 
kerangka konseptual dan rancangan penelitian, maka penelitian ini menggunakan teknik analisis SEM (Structural Equation Modeling), merupakan teknikteknik statistical, memungkinkan pengujian sebuah rangkaian hubungan yang relatif rumit dan simultan, (Ferdinand, 2002). Hubungan rumit itu dapat dibangun antara satu atau beberapa variabel terikat dengan satu atau beberapa variabel bebas merupakan teknik-teknik statistical, memungkinkan pengujian sebuah rangkaian hubungan yang relatif rumit dan simultan

\section{HASIL PENELITIAN DAN PEMBAHASAN}

Tanggapan responden terhadap variable penelitian: market orientation $\left(\mathrm{X}_{1}\right)$; service quality $\left(\mathrm{Y}_{1}\right)$; satisfaction $\left(\mathrm{Y}_{2}\right)$; serta loyalty $\left(\mathrm{Y}_{3}\right)$ ditunjukkan pada Table 3, keseluruhan menunjukkan respon hasil yang positif.

Nilai factor loading dan tingkat signifikasi dari masing-masing indikator digunakan sebagaimana disajikan pada Tabel 4, menunjukkan, market orientation diukur dengan indikator sebagai berikut:
Customer Orientation $\left(\mathrm{X}_{1}\right)$; Competitor Orientation $\left(\mathrm{X}_{2}\right)$; dan Interfunctional Coordination $\left(\mathrm{X}_{3}\right)$. Setiap indikator nilai $\mathrm{CR}>2.00$; $\mathrm{PV}<0,05$ dinyatakan signifikan dan dapat disimpulkan bahwa seluruh indikator market orientation (X) adalah valid, sehingga dapat dijadikan dimensi market orientation.

Tabel 5, menunjukkan service quality dapat diukur dengan indikator sebagai berikut: Reliability $\left(\mathrm{Y}_{1.1}\right)$; Responsiveness $\left(\mathrm{Y}_{1 \cdot 2}\right)$; Assurance $\left(\mathrm{Y}_{1 \cdot 3}\right)$; Empathy $\left(\mathrm{Y}_{1.4}\right)$; Tangibles $\left(\mathrm{Y}_{1.5}\right)$; Elemen Produk $\left(\mathrm{Y}_{1.6}\right)$; dan Promotion $\left(\mathrm{Y}_{1.7}\right)$. Setiap indikator yang nilai $\mathrm{CR}>2.00$; $\mathrm{PV}<0,05$ dinyatakan signifikan dan dapat disimpulkan bahwa seluruh indikator variabel service quality (Y) adalah valid, sehingga dapat dijadikan dimensi dari variabel service quality, sedangkan $\mathrm{Y}_{1.4}$ adalah reference variable.

Tabel 6 menunjukkan variable satisfaction diukur dengan indikator: $\left(\mathrm{Y}_{2.1}\right)$ yaitu Attributes related to the product; $\left(\mathrm{Y}_{2.2}\right)$ Attributes related to service; $\left(\mathrm{Y}_{2.3}\right)$ Attributes related to purchase. Setiap indikator yang nilai $\mathrm{CR}>2.00$; $\mathrm{PV}<0,05$ dinyatakan signifikan dan dapat disimpulkan bahwa seluruh indikator dari satisfaction variabel $\left(\mathrm{Y}_{2}\right)$ adalah valid, sehingga

Tabel 3. Hasil Analisia Deskripsi Variabel Penelitian

\begin{tabular}{lcclcccc}
\hline \multicolumn{1}{c}{ Variabel } & Indikator & Skor & & Variabel & Indikator & Skor & \\
\hline Market & $\left(\mathrm{X}_{1}\right) ;$ & 3.992 & Positif & Satisfaction & $\left(\mathrm{Y}_{21}\right) ;$ & 3.902 & Positif \\
Orientation & $\left(\mathrm{X}_{2}\right) ;$ & 3.874 & Positif & $\left(\mathrm{Y}_{2}\right) ;$ & $\left(\mathrm{Y}_{22}\right) ;$ & 3.830 & Positif \\
$\left(\mathrm{X}_{1}\right) ;$ & $\left(\mathrm{X}_{3}\right)$ & 4.108 & Positif & & $\left(\mathrm{Y}_{23}\right) ;$ & 4.175 & Positif \\
Service Quality & $\left(\mathrm{Y}_{1}\right) ;$ & 4.407 & Positif & Loyalty $\left(\mathrm{Y}_{3}\right) ;$ & $\left(\mathrm{Y}_{31}\right) ;$ & 4.256 & Positif \\
$\left(\mathrm{Y}_{1}\right) ;$ & $\left(\mathrm{Y}_{2}\right) ;$ & 4.006 & Positif & & $\left(\mathrm{Y}_{32}\right) ;$ & 4.173 & Positif \\
& $\left(\mathrm{Y}_{3}\right) ;$ & 4.130 & Positif & & $\left(\mathrm{Y}_{33}\right) ;$ & 4.888 & Positif \\
& $\left(\mathrm{Y}_{4}\right) ;$ & 3.967 & Positif & & $\left(\mathrm{Y}_{34}\right) ;$ & 4.118 & Positif \\
& $\left(\mathrm{Y}_{5}\right) ;$ & 4.080 & Positif & & & & \\
& $\left(\mathrm{Y}_{6}\right) ;$ & 3.962 & Positif & & & & \\
& $\left(\mathrm{Y}_{7}\right) ;$ & 3.793 & Positif & & & &
\end{tabular}

Sumber: Data primer diolah

Tabel 4. Construct Validity Market Orientation (X)

\begin{tabular}{ccccc}
\hline Indikator & Regression Weight (Factor Loading) Critical Ratio $(\mathbf{C R})$ & Probability $(\mathbf{P V})$ & Kriteria $(\mathbf{C R}>\mathbf{2 . 0})$ \\
\hline $\mathrm{X}_{1 .}$ & 0.877 & 12.824 & 0.000 & Signifikan \\
$\mathrm{X}_{2}$ & 0.975 & - & - & Ref. Variable \\
$\mathrm{X}_{3}$ & 0.812 & 12.257 & 0.000 & Signifikan \\
\hline
\end{tabular}

Sumber: Hasil Uji Statistik

Tabel 5. Construct Validity Service Quality ( $\left.\mathbf{Y}_{1}\right)$

\begin{tabular}{ccccc}
\hline Indikator & Regression Weight (Factor Loading) & Critical Ratio $(\mathbf{C R})$ & Probability $(\mathbf{P V})$ & Kriteria $(\mathbf{C R}>\mathbf{2 . 0})$ \\
\hline $\mathrm{Y}_{1.1}$ & 0.490 & 6.875 & 0.000 & Signifikan \\
$\mathrm{Y}_{1 \cdot 2}$ & 0.395 & 5.280 & 0.000 & Signifikan \\
$\mathrm{Y}_{1-3}$ & 0.432 & 6.198 & 0.000 & Signifikan \\
$\mathrm{Y}_{1 \cdot 4}$ & 1.003 & - & 0.000 & Ref. Variable \\
$\mathrm{Y}_{1 \cdot 5}$ & 0.212 & 2.910 & 0.000 & Signifikan \\
$\mathrm{Y}_{1 \cdot 6}$ & 0.477 & 6.640 & 0.000 & Signifikan \\
$\mathrm{Y}_{1 \cdot 7}$ & 0.993 & 98.781 & 0.000 & signifikan \\
\hline
\end{tabular}

Sumber: Hasil Uji Statistik 
Tabel 6. Construct Validity Satisfaction $\left(\mathbf{Y}_{2}\right)$

\begin{tabular}{ccccc}
\hline Indikator & RegressionWeight (Factor Loading) & Critical Ratio $($ CR) & Probability $(\mathbf{P V})$ & Kriteria $($ CR $>2.0)$ \\
\hline $\mathrm{Y}_{2.1}$ & 0.829 & - & 0.000 & Ref. Variable \\
$\mathrm{Y}_{2.2}$ & 0.751 & 9.494 & 0.000 & Signifikan \\
$\mathrm{Y}_{2.3}$ & 0.801 & 10.214 & 0.000 & Signifikan \\
\hline
\end{tabular}

Sumber: Hasil Uji Statistik

Tabel 7. Construct Validity Loyalty $\left(\mathbf{Y}_{3}\right)$

\begin{tabular}{ccccc}
\hline Indikator & RegressionWeight (Factor Loading) & Critical Ratio $(\mathbf{C R})$ & Probability $(\mathbf{P V})$ & Kriteria $(\mathbf{C R}>\mathbf{2 . 0})$ \\
\hline $\mathrm{Y}_{3.1}$ & 0.820 & - & - & Ref. Variable \\
$\mathrm{Y}_{3.2}$ & 0.760 & 9.463 & 0.000 & Signifikan \\
$\mathrm{Y}_{3.3}$ & 0.822 & 7.900 & 0.000 & Signifikan \\
$\mathrm{Y}_{3.4}$ & 0.651 & 6.331 & 0.000 & Signifikan \\
\hline
\end{tabular}

Sumber: Hasil Uji Statistik

dapat dijadikan dimensi satisfaction. Tabel 7 di bawah menunjukkan bahwa variabel loyalty dapat diukur dengan indikator: Berbelanja kembali ( $\left.\mathrm{Y}_{3.1}\right)$; Meningkatkan jumlah pembelian $\left(\mathrm{Y}_{3.2}\right)$; Menginformasikan kepada orang lain $\left(\mathrm{Y}_{3.3}\right)$ Memberi saran $\left(\mathrm{Y}_{3.4}\right)$. Setiap indikator yang nilai $\mathrm{CR}>2.00$; PV < 0,05 dinyatakan signifikan dan dapat disimpulkan seluruh indikator loyalty $\left(\mathrm{Y}_{3}\right)$ adalah valid, sehingga dapat dijadikan dimensi loyalty.

Menentukan nilai batas reliabilitas instrumen (construct reliability) dalam $\mathrm{SEM} \geq 0.7$ Hair et al. (1998) dapat dihitung dengan perumusan sebagai berikut: $\begin{aligned} \text { Construct reliability }= & \left(\sum \text { std. } \text { loading }\right)^{2} /\left(\sum \text { std } .\right. \\ \text { loading })^{2}+\sum e j & \text { e }\end{aligned}$

Hasil perhitungan data lapangan adalah:

1. Service Quality $=\frac{(4,00)^{2}}{(4,00)^{2}+3.37}=0,83>0,7$ (reliabel)

2. Market Orientation $=\frac{(2,66)^{2}}{(2,66)^{2}+0.37}=0,90>0,7$ (reliabel)

3. Satisfaction $=\frac{(2,38)^{2}}{(2,38)^{2}+1.11}=0,84>0,7$ (reliabel)

4. Loyalty $=\frac{(3,05)^{2}}{(3,05)^{2}+1,73}=0,84>0,7$ (reliabel)

Dari hasil perhitungan tersebut di atas, dapat disimpulkan bahwa alat ukur yang digunakan telah memenuhi persyaratan construct reliability.

\section{Pengaruh Market Orientation terhadap Service Quality}

Hasil temuan dalam penelitian ini membuktikan bahwa market orientation berpengaruh signifikan terhadap service quality yang dilakukan Toko Buku Gramedia di Jawa Timur. Hasil deskripsi penilaian responden menunjukkan penilaian pelanggan yang dijadikan responden ini terhadap variabel market orientation positif (3-4). Hasil (CFA) menunjukkan variabel market orientation lebih ditentukan oleh dimensi (indikator) yang memiliki loading factor besar, yaitu Orientasi pesaing; dan Orientasi pelanggan. Loading factor yang dihasilkan dari CFA juga menunjukkan variabel service quality lebih ditentukan dimensi yang memiliki loading factor besar, yaitu: empathy, promosi.

Toko Buku Gramedia mempunyai pengalaman cukup matang dalam mengelola toko buku, paling tidak mengetahui kekuatan dan kelemahan pesaing. Sebagai toko buku yang market leader tidak memandang enteng terhadap pesaing. Pesaing Toko Buku Gramedia bisa dibedakan menjadi dua yakni toko buku besar dan toko buku diskon (tradisionil). Terhadap pesaing khususnya toko buku diskon, tantangan yang paling berat adalah dalam persaingan harga. Ada beberapa pelanggan mempersepsikan harga buku di Gramedia mahal, namun sebagian besar mempersepsikan biasa. Kendala inilah yang harus dihilangkan, dengan cara memberi added value terhadap setiap pelanggan. Added value di sini bisa berupa penyediaan kelengkapan buku; buku-buku baru; best seller, pelayanan yang lebih baik serta fasilitas lebih nyaman. Dengan berfokus kepada pelanggang, berarti seluruh kemampuan yang dimiliki Toko Buku Gramedia ditujukan untuk meningkatkan layanan pelanggan, sehingga akan menimbulkan kesadaran seluruh karyawan dalam melayanani pelanggan. Misalnya karyawan atau staf tidak membeda-bedakan status pelanggan, memahami kebutuhan spesifik maupun keluahan pelanggan Toko Buku Gramedia di Jawa Timur. Antusiasme karyawan dalam meningkatkan service quality sangat dihargai perusahaan. Sebagai kompensasi, apabila 
target yang ditetapkan perusahaan tercapai akan ada insentip tiap tiga bulan sekali. Added value lainnya yakni adanya even promosi misalnya promosi berhadiah yang diselenggarakan setiap tahun menjelang tahun ajaran baru yakni bulan Juli sampai September. Best price (buku murah) setahun bisa berlangsung dua sampai tiga kali, serta even-even khususs menjelang tahun mahasiswa baru, potongan diskon $25 \%$ khusus untuk buku-buku mahasiswa. Even promosi ini berkat dukungan dan kerja sama dengan penerbit, supplier, bagian iklan (koran dan majalah) serta distributor sebagai supply chain mata rantai perdagangan buku dengan Toko Buku Gramedia di Jawa Timur. Hasil penelitian ini menguatkan pendapat dari Tsai (2003). Indikator pertama paling kuat pembentuk variabel market orientation mempunyai nilai positif di benak konsumen Toko Buku Gramedia, bila dibanding kompetitor. Kepercayaan ini harus dipertahankan atau ditingkatkan agar pelanggan tidak lari ke kompetitor. Indikator yang paling lemah adalah interfunctional coordination. Ini mengindikasikan bahwa koordinasi antar bagian belum padu, sehingga pimpinan maupun staf harus menyadari bahwa komunikasi antar bagian sangat penting, terutama menyangkut layanan pelanggan. Perlu adanya standarisasi pelayanan, sehingga pelanggan tidak bingung. Perlu memperbaiki terus menerus atas kelemahan dalam melayani pelanggan

\section{Pengaruh Market Orientation terhadap Satisfaction}

Hasil penelitian menunjukkan market orientation berpengaruh signifikan terhadap satisfaction pelanggan Toko Buku Gramedia di Jawa Timur. Hipotesis kedua terbukti Loading factor yang dihasilkan dari $C F A$ juga menunjukkan variabel satisfaction lebih ditentukan oleh dimensi (indikator) yang memiliki loading factor besar yaitu attribute relate to the product dan Attribute relate to purchase. Hal ini mengindikasikan bahwa kelengkapan produk maupun kemampuan karyawan dalam melayani memberikan pengaruh cukup besar terhadap kepuasan pelanggan Toko Buku Gramedia di Jawa Timur. Fakta di lapangan menunjukkan bahwa Toko Buku Gramedia merupakan barometer terhadap kelengkapan produk baik produk best seller maupun buku-buku baru di Indonesia. Hampir sebagian besar produk yang tidak dijual di toko buku pesaing ada di Toko Buku Gramedia. Hubungan dengan mata rantai perdagangan buku khususnya penerbit, distributor dan agen titipan paket mempunyai kerja sama yang baik. Kerjasama dapat dilukiskan sebagai aktivitas terkoordinasi yang dilakukan perusahaan terkait dalam supply chain, kemitraan menghasilkan outcome ber- mutu serta bertujuan memuaskan pelanggan. Fokus terhadap kebutuhan pelanggan memberikan dampak terhadap satisfaction. Hal tersebut sejalan dengan penelitian Bigne \& Blesa (2003) bahwa market orientation memiliki pengaruh positif atas kepercayaan dan kepuasan distribusi.

Pengaruh langsung market orientation terhadap loyalty tidak signifikan. Ini ditandai dengan loading factor besarnya 0,004 . Di sini loyalty tidak ditentukan oleh kelengkapan produk (harga dan kualitas) ataupun layanan yang baik. Loyalty dalam penelitian ini ditentukan satu aspek yaitu satisfaction sehingga satisfaction merupakan kunci menuju ke loyalty pelanggan. Secara empiris bahwa pelanggan yang loyal adalah pelanggan sudah mendapatkan kepuasan, namun tidak sebaliknya, pelanggan yang puas belum tentu loyal. Sedang pengaruh tidak langsung yaitu lewat satisfaction, mempunyai pengaruh yang signifikan. Satisfaction sebagai variabel intervening mampu mendorong menaikkan pengaruh tidak langsung market orientation terhadap loyalty. Untuk kepentingan masa depan, perusahaan seharusnya memfokuskan strategi utama yakni memuaskan pelanggan secara maksimal agar tercapai loyalty.

\section{Pengaruh Service Quality terhadap Satisfaction}

Hasil temuan penelitian membuktikan service quality berpengaruh signifikan terhadap satisfaction. Dari hasil (CFA) menunjukkan, variabel service quality lebih ditentukan oleh dimensi yang memiliki loading factor besar yaitu empathy; dan promosi. Layanan, perhatian terhadap keluhan dan kebutuhan, sangat berdampak terhadap kepuasan pelanggan. Dampak terhadap kepuasan di dalam hal ini diwakili oleh attribute relate to purchase (berhubungan dengan pembelian). Promosi juga menambah keyakinan pelanggan, khususnya promosi potongan harga akan menghapus kesan terhadap buku-buku yang dijual di Toko Buku Gramedia mahal. Untuk indikator service quality paling lemah adalah tangible (fasilitas fisik). Ini mengindikasikan bahwa fasilitas yang dimiliki oleh Toko Buku Gramedia masih kurang menunjang. Item-item dari indikator tangibles yang perlu dibenahi di antaranya adalah: fasilitas parkir, lay out toko jaminan keamanan dan fasilitas pendingin ruangan serta tempat penitipan barang. Pembenahan guna meningkatkan satisfaction pelanggan Toko Buku Gramedia di Jawa Timur.

Dalam penelitian ini dimensi service quality yang digunakan adalah kolaborasi antara Zeithaml $e t$ al. (1994) dan konsep service dari Lovelock \& Wright (2005), yang terdiri tujuh indikator. Berdasarkan uji penelitian, ketujuh indikator tersebut merupa- 
kan indikator-indikator yang secara signifikan terbukti membentuk variabel service quality. Hasil penelitian Zeithaml et al. (1994) menyatakan bahwa service quality dibentuk kelima indikatornya. Hasil ini juga memperkuat penelitian Sureshchandar et al. (2002).

Pengaruh service quality terhadap loyalty sangat lemah dan tidak signifikan. menolak hipotesis kelima. Hal ini dapat dikatakan bahwa pelanggan beranggapan bahwa service quality (kualitas layanan) yang diberikan Toko Buku Gramedia belum menjamin loyalty harus dilalui lewat kepuasan, tanpa kepuasan tidak akan tercapai loyalty pelanggan. Hasil penelitian ini tak jauh berbeda dengan penelitian (Sutanto, 2003). Pengaruh tidak langsung lewat satisfaction mempunyai pengaruh cukup kuat. Ini berarti bahwa satisfaction sebagai variabel intervening mampu mendorong menaikkan pengaruhtidak langsung service quality terhadap layalty. Oleh sebab itu perusahan harus mempunyai strategi meningkatkan satisfaction guna menunjang loyalty pelanggan.

Pengaruh satisfaction terhadap loyalty membuktikan bahwa satisfaction berpengaruh signifikan terhadap loyalty pelanggan toko buku Gramedia. Hipotesis keenam terbukti. Hasil $C F A$ menunjukkan variabel loyalty lebih ditentukan oleh dimensi keinginan berbelanja kembali; serta menginformasikan kepada orang lain untuk berbelanja, sehingga tipe pelanggan Gramedia adalah pembeli berulang, klien dan advocate. Pengaruh satisfaction pelanggan di sini diantaranya: harga murah; berkualitas (bukan bajakan) dan banyak pilihan. Apabila satisfaction pelanggan tersebut telah terpenuhi dampaknya adalah pelanggan akan selalu datang untuk berbelanja kembali; menginformasikan kepada teman atau orang lain mengenai hal-hal yang positif dan menyarankan untuk selalu berbelanja ke Toko Buku Gramedia di Jawa Timur

Hasil penelitian ini menyatakan bahwa responden memberikan penilaian netral terhadap harga buku di Toko Buku Gramedia. Sebenarnyaharga buku ditetapkan leh penerbit. Perbedaan harga disebabkan karena adanya diskon atau potongan, sistem pembelian dan lainnya. Begitu juga dengan citra toko buku yang baik serta kemampuan menjual berpengalaman dengan semboyan 4S (senyum, salam, sapa dan santun) akan berdampak terhadap loyalty pelanggan. Penelitian Silvadas et al. (2000) tidak sependapat dengan penelitian ini, satisfaction tidak berpengaruh langsung terhadap loyalty pelanggan retail departement di USA. Indikator paling lemah adalah attribute related to service. Ini mengidikasikan bahwa attribute related to services belum sepenuhnya memuaskan pelanggan. Indikator ini terdiri dari itemitem a) Gramedia bersedia mengganti buku yang cacat, b) karyawan Gramedia cepat tanggap dalam menangani keluhan pelanggan, c) karyawan membantu menyelesikan masalah yang pelanggan hadapi. Artinya bahwa apabila pelanggan dalam membeli buku, ternyata ada beberapa halaman yang kurang lengkap, atau dobel akan diganti dengan yang baru masih disangsikan. Toko Buku Gramedia harus memperbaiki sistem layanan dalam penjualan. Karena menyangkut kepuasan, menjadi satu-satunya tujuan ke loyalty

Indikator loyalty dibentuk dengan mengkolaborasikan Konsep Bowen \& Chen (2001) serta Konsep Griffin (2003). Hasil penelitian menunjukkan semua indikator yang membentuk loyalty pelanggan kuat dan signifikan. Indikator pembentuk variabel loyalty tersebut adalah : a) Keinginan berbelanja kembali. b) Meningkatkan jumlah pembelian. c) Menginformasikan kepada orang lain. d) Memberi saran kepada Gramedia. Keempat item tersebut merupakan kolaborasi antara Bowen \& Chen (2001) dengan Griffin (2003) Pengaruh semua indikator dalam membentuk variabel loyalty kuat dan signifikan. Kontribusi paling kuat dalam indikator loyalty pelanggan adalah menginformasikan kepada orang lain, artinya pelanggan akan mempromosikan baik produk/service kepada keluarga, teman supaya berbelanja di Toko Buku Gramedia. Indikator kedua pembentuk variabel loyalty adalah keinginan untuk berbelanja kembali. Ini berarti pelanggan bersedia berbelanja kembali (repeat purchase), karena pembelian pertama, pelanggan menemukan kepuasan dalam berbelanja. Hasil penelitian ini searah dengan penelitian dari Silvadas et al. (2000) bahwa pembelian ulang secara signifikan mempengaruhi loyalty pelanggan Deptartement Store di USA.

Indikator ketiga yaitu meningkatkan jumlah pembelian, Ini menunjukkan bahwa apa yang dirasakan pelanggan tentang satisfaction yang diberikan Toko Buku Gramedia mempunyai manfaat sangat besar bagi pelanggan sehingga pelanggan dengan senang hati akan meningkatkan jumlah pembelian yang lebih besar dari pembelian sebelumnya.

\section{SIMPULAN DAN SARAN}

Dari hasil pengolahan dan analisis data dengan menggunakan (SEM) terdapat beberapa simpulan, yaitu: (a) Ada pengaruh signifikan market orientation terhadap service quality pelanggan toko buku Gramedia Jawa Timur (b) Ada pengaruh signifikan market orientation terhadap satisfaction pelanggan toko buku Gramedia Jawa Timur. (c) Tidak ada pengaruh yang signifikan market orientation terhadap loyalty pelanggan toko buku Gramedia Jawa Timur. 
(d) Ada pengaruh signifikan service quality terhadap satisfaction pelanggan toko buku Gramedia Jawa Timur. (e) Tidak ada pengaruh signifikan service quality terhadap loyalty. (f) Ada pengaruh signifikan Variabel satisfaction terhadap loyalty pelanggan toko buku Gramedia Jawa Timur

Atas dasar penelitian, analisis data dan pembahasan di atas yang dilakukan oleh peneliti, maka berikut ini ada beberapa saran-saran yang disampaikan sebagai berikut: Kepada Manajemen Toko Buku Gramedia Jawa Timur, pengaruh service quality dan market orientation secara bersama-sama menunjukkan kontribusi yang besar terhadap satisfaction. Namun service quality dan market orientation secara langsung tidak signifikan terhadap loyalty. Diharapkan perusahaan mengembangkan strategi tersebut market orientation dan service quality secara bersama-sama.

Satisfaction merupakan tujuan perusahaan, hendaknya komitmen tersebut dipegang teguh bukan hanya lewat ucapan melainkan harus dengan tindakan tegas. Hendaknya perusahaan perlu memperbaiki khususnya yang berkenaan dengan attributes relate to service. Kelemahan indikator tersebut akan menghambat terbentuknya satisfaction. Satisfaction di sini berperan sangat penting, karena loyalty hanya bisa diraih harus melalui satisfaction, oleh sebab itu maksimalkan satisfaction bagi setiap pelanggan. Bagi peneliti selanjutnya pengembanhan loyalty agar tidak menggelobal, harus dikelompokkan berdasarkan loyalty kognitif, afektif maupun konatif. Hal ini agar mudah diketuhui kelompok loyalty mana yang paling dominan dalam penelitian itu.

\section{DAFTAR REFERENSI}

Berman, B. \& Evans, J. R. 2004. Retail Management: A Strategy Approach. Ninth Edition. New Jersey: Pearson Prentice Hall.

Bigne, E. \& Blesa, A. 2003. Market Orientation, Trust and Satisfaction in Dyadic relationships: a Manufacturer-Retailer Analysis, International Journal of Retail and Distribution Management, 31(11): 574-590.

Bly, R. W. 2003. Fool Prof. Marketing. Jakarta: Penerbit Erlangga.

Bowen, J. T. \& Chen, S. L. 2001. The Relationship Between Customer Loyalty and Customer Satisfaction. International Journal of Contemporary Hospitality Management, 13(5): 213217.

Chang, T. Z. \& Chen, S. J. 1998. The Relationships Among Market Orientation, Service Quality and Busuness Profitability. The Journal of Service Marketing, 12(4): 246-258.
Cronin, J., Joseph, M. K., Brandy \& Thomas, M. H. 2000. Assessing the Effects of Quality, Value and Customer Satisfaction on Consumer Behavioral Intention In Service Environment. Journal of Retailing, 76(2): 193-218.

Deshpande, R. \& Farley, J. U. 1998. Measuring Market Orientation: Generalization and Synthesis. Journal of Market Focused Management, 2: 213-232.

Deshpande, R., Farley, J. U. \& Webster, F. E. 1993. Corporate Culture, Customer Orientation and Innovativeness in Japanese Firm: A Quadrad Analysis. Journal of Marketing, 58: 1-19.

Dutka, A. 1994. AMA Handbook for Customer Satisfaction: A Complete Guidance to Research, Planning and Implementation. Illinois: NTC Business Book.

Ferdinand, A. 2002. Structural Equation Modeling Dalam Penelitian Manajemen. Semarang: Badan Penerbit Universitas Diponegoro.

Fornell, C. 1992. A National Customer Satisfaction Barometer: The Swedish Experience. Journal of Marketing, 56(2): 7-18.

Griffin, J. 2003. Customer Loyalty (Loyalitas Pelanggan). Jakarta: Erlangga.

Hopson, B. \& Scally, M. 1995. 12 Steps to Success Through Service. Oxon Books 2000.

Irawan, H. 2002. 10 Prinsip Kepuasan Pelanggan: Paradigma Baru Merebut Hati Pelanggan Untuk Memenangkan Persaingan. Jakarta: Elex Media.

Jaworski, B. J. \& Kohli, A. K. 1993. Marketing Orientation: Antecedent and Consequences. Journal of Marketing, 57: 53-70.

Kohli, A. K. \& Jaworski, B. J. 1990. Market Orientation: The Construct, Research Proposition and Managerial Implications. Journal of Marketing, 54: $1-18$

Kotler, P. 2000. Marketing Management: Analysis, Planning, Implementation and Control. Millenium Edition. New Jersey: Prentice Hall International Inc.

Kotter, J. P. and Heskett J. L. 1992, Corporate Culture and Performance. New York: Simon Schuster.

Lovelock \& Wright. 2005. Manajemen Pemasaran Jasa. Jakarta: Index.

Narver, J. C. \& Slater, S. F. 1990. The Effect of Market Orientation on Business Profitability. Journal of Marketing, 54: 20-35.

Oliver, R. L. 1997. Response Determinants in Satisfaction Judgements. Journal of Custumer Research, 14(03): 495-507. 
Pelham, A. M. \& Wilson, D. T. 1996. A Longitudinal Study of The Impact of Market Structure Firm Structure Strategy and Market Orientation Culture on Dimention of Small Firm Performance. Journal of The Academy of Marketing Science, 24(1): 27-43.

Pritchard, M. P. \& Howard, D. R. 1997. The Loyal Traveler: Examining a Typology of Service Patronage. Journal of Travelers Research, 35(4): 2-11.

Silvadas, E., Baker, J. L. \& Prewitt. 2000. An Examination of the Relationship between Service Quality, Customer Satisfacton, and Store Loyalty. International Journal of Retail and Distribution Management, 28(2): 73-84.

Singarimbun, M. 1995. Pengantar Statistika Lanjutan Edisi Keempat. Jakarta: Penerbit LP3ES.
Sureshchandar, G. S., Rajendran, C. \& Anantharaman, R. N. 2002. The Relationship Between Service Quality and Customer Satisfaction a Factor Specific Approach. Journal of Services Marketing, 16(4): 363-379.

Sutanto, J. A. 2003. Pengaruh Service Quality dan Perceived Value Terhadap Kepuasan dan Loyalitas Konsumen Kondominium Di Kota Surabaya. Disertasi tidak dipublikasikan. Surabaya: Universitas 17 Agustus 1945.

Thoyib, U. 1998. Manajemen Perdagangan Eceran 1, Yogyakarta: Ekonisia.

Tjiptono, F. \& Chandra, G. 2005. Service, Quality and Satisfaction. Yogyakarta: Andi Offset.

Zeithaml, Valarie, A., Berry, L. \& Parasuraman, A. 1994. The Behavioral Consequences of Service Quality. Journal of Marketing, 60: 31-46. 